\title{
Scanning electrochemical microscopy imaging of poly $(3,4-$ ethylendioxythiophene)/thionine electrodes for lactate detection via NADH electrocatalysis
}

\author{
Susan Warren $^{\mathrm{a}, 1}$, Grigore Munteanu ${ }^{\mathrm{a}}$, Dhanraj Rathod ${ }^{\mathrm{a}, 2}$, Timothy McCormac ${ }^{\mathrm{b}}$, \\ Eithne Dempsey,* \\ ${ }^{a}$ Centre of Applied Science for Health (CASH), TU Dublin - Tallaght Campus, Dublin 24, Ireland \\ ${ }^{\mathrm{b}}$ Dundalk Institute of Technology, Dundalk, Co. Louth, Ireland \\ ${ }^{\mathrm{c}}$ Department of Chemistry, Maynooth University, Maynooth Co. Kildare, Ireland
}

A R T I C L E I N F O

\section{Keywords:}

Thionine

Poly-3,4-ethylenedioxythiophene (PEDOT)

Multiwalled carbon nanotubes (MWNT)

Lactate biosensor

Lactate dehydrogenase (LDH)

Scanning electrochemical microscopy (SECM)

Charge transport studies

\begin{abstract}
A B S T R A C T
Herein we report the use of scanning electrochemical microscopy (SECM) together with electrochemical and spectroscopic techniques to develop and characterise a stable and uniformly reactive chemically modified platinum electrode for NADH electrocatalysis. In order to achieve this, a range of different approaches for thionine entrapment within an electropolymerised poly (3,4-ethylendioxythiophene) (PEDOT) film were evaluated using SECM imaging in the presence of $\mathrm{NADH}$, demonstrating the uniformity of the reactive layer towards NADH oxidation. The effect of electrolyte type and time scale employed during PEDOT electropolymerisation was examined with respect to thionine loading and the resulting charge transport diffusion coefficient $\left(D_{\mathrm{CT}}\right)$ estimated via chronoamperometry. These studies indicated a decrease in $\mathrm{D}_{\mathrm{CT}}$ as thionine loading increased within the PEDOT film, suggesting that charge transport was diffusion limited within the film. Additionally, thionine functionalised nanotubes were formed, providing a stable support for lactate dehydrogenase entrapment while lowering the rate of thionine leaching, determined via SECM imaging. This enabled lactate determination at $\mathrm{E}_{\mathrm{app}}=0.0 \mathrm{~V}$ vs $\mathrm{Ag} / \mathrm{AgCl}$ over the range $0.25-5 \mathrm{mM}$ in the presence of $1 \mathrm{mM} \mathrm{NAD}^{+}$.
\end{abstract}

\section{Introduction}

More than 400 dehydrogenase enzymes catalyse reactions in the presence of their cofactor, nicotinamide adenine dinucleotide $\left(\mathrm{NAD}^{+}\right)$ or nicotinamide adenine dinucleotide phosphate $\left(\mathrm{NADP}^{+}\right)$, which act as the electron and hydrogen acceptor in the reaction catalysed by the enzyme to generate the reduced $\mathrm{NAD}(\mathrm{P}) \mathrm{H}$ coenzyme (Jing-Li et al., 2009).

Direct electrochemical oxidation of NAD(P)H is achievable on bare electrodes, however its high overpotential can lead to undesirable side reactions and is subject to interferences from electroactive materials within a sample matrix (ascorbic and uric acids). Many organic mediators have been investigated to help overcome this, the majority of which possess a quinone or phenyldiimine structure. Examples of such materials include organic dyes e.g. Meldola's Blue (Maroneze et al., 2008; Vasilescu et al., 2003a, 2003b; Prieto-Simón et al., 2007), methylene green/blue (Rincon et al., 2010; Al-Jawadi et al., 2012) Nile Blue A (Du et al., 2007), Prussian Blue (Gurban et al., 2008; Rejeb et al., 2007) and thionine (Gao et al., 2003; Persson and Gorton, 1990; Passos et al., 2010; Meng et al., 2008). One of the main issues with these redox active dyes is their high water solubility, which causes them to readily diffuse from their immobilised state at the electrode surface into the bulk solution. In addition to ease of surface attachment and stability, ensuring facile charge transport between immobilised redox sites is important such that the whole redox film contributes to NADH oxidation (Ashok Kumar and M Chen, 2008).

There have been some reports of non-covalent modification of carbon nanotubes with functional molecules such as $\mathrm{NAD}^{+}$(Zhou et al., 2010) and thionine (Wang et al., 2007). The positive charge of these molecules in solution enables adsorption onto nanotube walls via $\pi-\pi$ stacking interactions and so anchors the mediator to a stable support material. Prevention of aggregation and improved solubilisation of

\footnotetext{
${ }^{*}$ Corresponding author.

E-mail address: eithne.dempsey@mu.ie (E. Dempsey).

${ }^{1}$ Present address: CREST Technology Gateway, FOCUS Research Institute, Technological University Dublin, Kevin St, Dublin Ireland.

${ }^{2}$ Present address: Cefa-Cilinas Biotics Pvt Ltd, Aurangabad, Maharashtra, India.
} 
nanotubes has been an area of significant interest and has obtained some success via attachment of polymers (Riggs et al., 2000), and ionic modification with dispersion with surfactants (Vigolo et al., 2000). Bandyopadhyaya et al. (2002) presented an alternative to these approaches through non-specific physical adsorption of the biopolymer Gum Arabic, and proposed the use of a $0.5-15 \%$ wt solution which allows for a stable aqueous suspension of full length tubes, which can be dried and resuspended with ease. The application of conducting polymers as an immobilisation matrix for redox materials and biological components has achieved much attention (Ates, 2013; Jain et al., 2017; Xia et al., 2010; Malhotra et al., 2006; Gerard et al., 2002) and recent reports regarding the use of PEDOT describe the immobilisation of catechin (Vasantha and Chen, 2006) and 4-phenyl azo aniline (Balamurugan and Chen, 2008) for the electrooxidation of NADH. Balamurugan et al. (2010), describe a PEDOT coated electrode modified with silver nanoparticles and Meldola's Blue for NADH detection with minimal interference of electroactive compounds.

Scanning electrochemical microscopy (SECM) has been proven experimentally to be a very versatile technique for the visualisation of localised chemical and electrochemical activity within surface confined films and is the subject of recent reviews (Polcari et al., 2016; Zoski, 2016; Amemiya et al., 2008). It is based on a scanning microelectrode in close contact with a surface of interest with current dependant on local concentration of electroactive species, realising electron transfer kinetics, high resolution imaging and topography examinations (Morkvenaite-Vilkoncience et al., 2017). SECM can pattern the substrate surface, visualise its topography and prove chemical reactivity on the $\mu \mathrm{m}$ or nm scale (Sun et al., 2007).

Unlike STM and AFM tips which are sharp cones, a typical SECM tip is a conductive disk surrounded by a flat ring of insulating glass. This ultramicroelectrode (UME), capable of moving in $\mathrm{x}, \mathrm{y}$ and $\mathrm{z}$ directions, is positioned very close to an interface, and can be used to investigate the topography, reactivity or permeability of that surface with high spatial resolution (Wipf et al., 2001). The tip can induce chemical changes and collect electrochemical information while approaching or scanning the surface of interest, which can be biased, serving as the second electrode (Sun et al., 2007).

Studies of redox enzymes commonly utilise either feedback or generation/collection modes, both tip and substrate currents being measured in the latter case. In Substrate Generation - Tip Collection (SG-TC) mode, the tip probes reactions that occur at a substrate, which is held at a constant potential while the tip travels within a thick diffusion layer generated by the substrate electrode. When scanning in the $\mathrm{x} / \mathrm{y}$ direction over the substrate, the tip can identify hot spots where reactions occur at higher rates (Kai et al., 2018). In this mode, an enzyme causes regeneration of a mediator species, which is consumed at the ultramicroelectrode and the rate of the enzyme reaction is transduced into current measured by the SECM. The magnitude of the feedback response depends on the rate at which the enzyme catalytically regenerates the bulk form of the species (Pierce et al., 1992).

The theory and experimental applications of SECM - induced transfer (SECMIT) has been described by Barker et al. (1998), as an approach for probing partitioning of electroactive solutes between two immicible phases. The equilibrium is perturbed by electrolysis of the target species at the UME tip which is placed close to the interface with the second phase. Gonsalves et al. (2000) have employed the induced transfer (SECMIT) mode of SECM to image the permeability of methyl viologen in articular cartilage. By scanning the UME over the sample surface, detection of methyl viologen was performed amperometrically via the UME.

Prior work in our group has reported a Thionine/PEDOT catalytic layer for NADH oxidation (Warren et al., 2010). Here we advance the work with exploitation of thionine functionalised carbon nanotubes (MWNTs) using Gum Arabic as suspension reagent, in order to limit leaching of thionine from the electrode surface and to further exploit amine functionalities as a linker group for enzyme attachment. The characterisation and performance of thionine modified carbon nanotubes as a support for the stabilisation of thionine on the electrode surface and for the fixation of lactate dehydrogenase is examined here for the first time, realising successful lactate detection. Complementary electrochemical characterisation and SECM imaging evaluate the films via different modes, SECMIT and Substrate Generation-Tip collection (SG-TC), allowing for optimisation of the immobilisation method in terms of thionine uniformity, reactivity and stability.

\section{Experimental}

\subsection{Instrumentation and reagents}

All electrochemical experiments were carried out on a CHI 1030 or CHI 660a electrochemical workstation ( $\mathrm{CH}$ Instruments). A singlecompartment electrochemical cell was used with platinum counter electrode and a saturated $\mathrm{Ag} / \mathrm{AgCl}$ reference for aqueous solutions. Working electrodes were $3 \mathrm{~mm}$ diameter platinum discs. SECM analysis was carried out using a CHI920 bipotentiostat/SECM equipped with an adjustable stage for tilt correction. The tip electrodes used were 10 and $25 \mu \mathrm{m}$ platinum microelectrodes obtained from $\mathrm{CH}$ Instruments. RG values of 5-10 were calculated based on $R G=r_{g} /$ a where $r_{g}$ is the outer radius of the insulating sheath and $a$ is the microelectrode radius. UV Spectroscopy was carried out on a T80 UV-Visible spectrometer - PG Instruments. SEM analysis was performed using a Joel LV-6390.3,4ethylene dioxythiophene/EDOT, $\mathrm{LiClO}_{4}$, sodium $p$-toluene sulphonate, thionine acetate, ethanol, nitric acid, multiwall carbon nanotubes, Gum Arabic, NADH, $\mathrm{NAD}^{+}$, lactate dehydrogenase 579 units/mg (USB), 25\% glutaraldehyde, sodium lactate, ferrocene methanol, phosphate buffered saline $(\mathrm{pH}$ 7.4) were received from Sigma Aldrich and used as received unless otherwise specified.

\subsection{Procedures}

\subsubsection{Preparation of thionine modified functionalised multiwalled carbon nanotubes (Th-fMWNT's)}

$100 \mathrm{mg}$ of multiwalled carbon nanotubes (MWNTs) was sonicated in deionised water for $30 \mathrm{~min}$, followed by filtration through a polycarbonate membrane. The solid was washed several times with deionised water, ensuring the filtrate was clear. The washed solid was then refluxed in $10 \% \mathrm{HNO}_{3}$ at $80{ }^{\circ} \mathrm{C}$ for $24 \mathrm{~h}$ with vigorous stirring. The acid solution was filtered through a hydrophobic PTFE (polytetrafluoroethylene) membrane, followed by washing with deionised water and acetone several times. The acid functionalised MWNT's (fMWNTs) were then dried at $110^{\circ} \mathrm{C}$ for $12 \mathrm{~h}$ under vacuum. $2 \mathrm{mg}$ of fMWNT were suspended in $2 \mathrm{~cm}^{3}$ deionised water with the aid of mild sonication (400 W). 100-150 $\mu \mathrm{M}$ thionine was added to the suspension and shaken for ca. 2 min until the solution turned clear and the nanotubes fell out of suspension, indicating absorption of thionine onto the nanotubes. Gum Arabic was added to the solution to a final concentration of $1 \%$ and sonication was carried out to re-suspend the modified nanotubes, denoted Th-fMWNT.

\subsubsection{Lactate dehydrogenase attachment to Th-fMWNT (LDH-Th- fMWNT)}

$7.6 \mu \mathrm{l}$ of $2.5 \%$ glutaraldehyde was added to a stable suspension of Th-fMWNT's $\left(2 \mathrm{~cm}^{3}\right)$ and stirred for $1 \mathrm{~h}$ to activate the amine groups on the thionine. Meanwhile lactate dehydrogenase was dissolved in $2 \mathrm{~cm}^{3}$ PBS and mixed with the Th-fMWNT/glutaraldehyde solution. Stirring was maintained for a number of hours at room temperature and the solution was maintained at $4{ }^{\circ} \mathrm{C}$ overnight. Modification of Pt electrodes with this material was achieved by depositing $5 \mu \mathrm{L}$ of the solution onto the surface of the electrode and allowing it to air dry for $\sim 30 \mathrm{~min}$.

\subsubsection{Electrochemical procedures}

Pt electrodes were cleaned by polishing with alumina slurries $(1,0.5$ 
(A) NADH Reactivity

$$
\mathrm{E}_{\text {(tip) }}=+0.1 \mathrm{~V} v \mathrm{~s} . \mathrm{Ag} / \mathrm{AgCl}
$$

$$
E_{(t i p)}=+0.4 V v s . A g / A g C l
$$
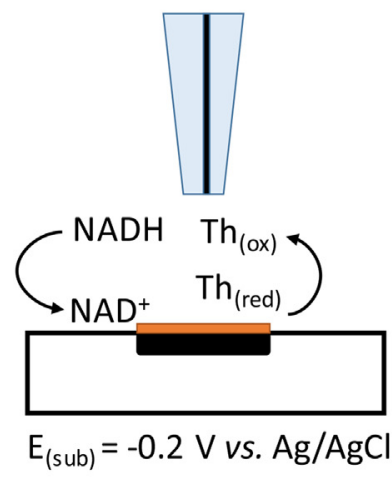

PEDOT/Thionine layer
(B) Thionine Stability

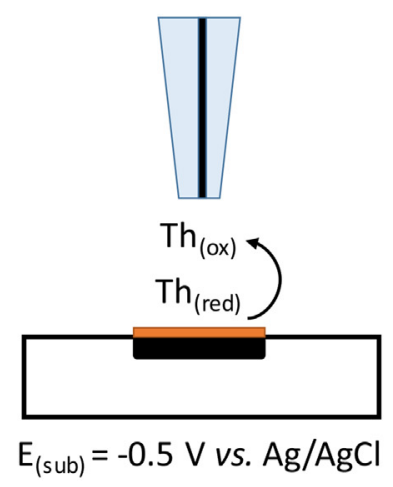

PEDOT/Thionine layer
(C) LDH activity @ PEDOT/Th-fMWNT layer

$\mathrm{E}_{(\text {tip })}=+0.3 \mathrm{~V} v$ s. $\mathrm{Ag} / \mathrm{AgCl}$

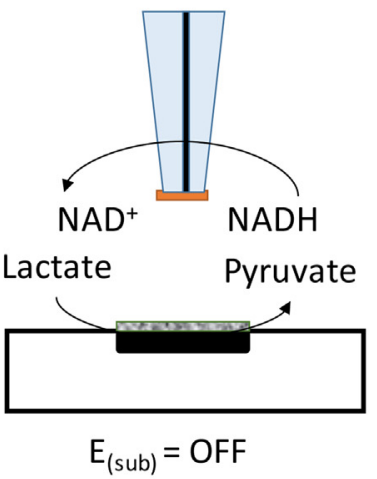

LDH-Th-fMWNT

Scheme 1. Schematics representing the modes substrate generation tip collection (a) and (c) and SECM induced transfer (b) applied for SECM imaging experiments.

and $0.05 \mu \mathrm{m}$ ) with washing and gentle sonication in between each grade. Prior to polymer deposition the electrode was electrochemically activated in $0.5 \mathrm{M} \mathrm{H}_{2} \mathrm{SO}_{4}$ via potential cycling between -1.5 and + $1.5 \mathrm{~V}$ vs. $\mathrm{Ag} / \mathrm{AgCl}$ with stirring, followed by holding the electrode at $-1.5 \mathrm{~V}$ vs. $\mathrm{Ag} / \mathrm{AgCl}$ for $900 \mathrm{~s}$, with stirring.

2.2.3.1. Formation of Thionine-PEDOT and PEDOT/Thionine films. Thionine-PEDOT films were prepared as described previously (Warren et al., 2010). Briefly, films were formed from $10 \mathrm{mM}$ thionine acetate, $15 \mathrm{mM}$ EDOT in $10 \mathrm{mM} \mathrm{LiClO}_{4}$ via chronocoulometry $(5 \mathrm{mC}$ charge passed at $\mathrm{E}_{\mathrm{APP}} 1.2 \mathrm{~V}$ vs. $\mathrm{Ag} / \mathrm{AgCl}$ ). In the case of PEDOT/ Thionine and PEDOT/Th-fMWNT films an activated Pt electrode was modified with PEDOT using chronocoulometry to form a $79.6 \mathrm{mC} \mathrm{cm}^{-2}$ film - $\mathrm{E}_{\mathrm{APP}}+1.2 \mathrm{~V}$ vs $\mathrm{Ag} / \mathrm{AgCl}$ from a solution of $10 \mathrm{mM}$ EDOT aqueous solution with $0.1 \mathrm{M}$ electrolyte. Thionine was then incorporated into this film by placing the PEDOT modified electrode in a $0.5 \mathrm{mM}$ aqueous thionine solution and holding the applied potential at $-0.5 \mathrm{~V}$ vs. $\mathrm{Ag} /$ $\mathrm{AgCl}$ for various time periods (15-90 min). The electrode was then rinsed with deionised water prior to use. For inclusion of Th-fMWNT, the same procedure was followed, where a stable suspension of the ThfMWNT's replaced the thionine solution.

2.2.3.2. Charge transport diffusion coefficient $\left(D_{C T}\right)$ determination by chronoamperometry. The PEDOT/Thionine modified (Pt) electrodes were analysed in PBS $\mathrm{pH}$ 7.4. The electrodes were first subjected to potential cycling at $0.1 \mathrm{~V} \mathrm{~s}^{-1}(-0.7 \rightarrow+0.4 \mathrm{~V}$ vs. $\mathrm{Ag} / \mathrm{AgCl}$, for 25 cycles) and then $5 \mathrm{mV} \mathrm{s}^{-1}$ for 3 cycles (over the same range) to ensure any loosely bound thionine was removed from the electrode surface, and that stable currents were obtained. Two sets of potentials were determined from the stable CV. For background measurements, the potentials were chosen where no redox reaction occurs, i.e. potentials prior to oxidation and following the reduction wave; normally -0.7 to $-0.6 \mathrm{~V}$ vs. $\mathrm{Ag} / \mathrm{AgCl}$. This single step measurement was carried out 5 times and an average current obtained. For the actual measurements, the potential was stepped from a region prior to thionine oxidation i.e. $-0.7 \mathrm{~V}$ vs. $\mathrm{Ag} / \mathrm{AgCl}$, to a region where the current was diffusion controlled, typically $+0.35 \mathrm{~V}$ vs. $\mathrm{Ag} / \mathrm{AgCl}$. This current measurement was taken 5 times and averaged. Background subtraction was then applied to the averaged results.

\subsubsection{Film preparation on ITO slides - UV analysis}

ITO slides were cleaned with IPA, followed by soaking in $10 \%$ $\mathrm{NaOH}$ at $55^{\circ} \mathrm{C}$ for $3 \mathrm{~min}$, after which the slides were rinsed with deionised water and dried to ensure no water marks were present prior to use. Cleaned slides were stored in ethanol until use, with adequate rinsing with deionised water and drying prior to use. A specific area $\left(\sim 1 \mathrm{~cm}^{2}\right)$ was marked off using masking tape to allow for accurate film measurements. Once the films were formed on the surface as described above, the modified slides were soaked in deionised water until the leaching of loosely bound thionine had ceased. The films were then allowed to dry under ambient conditions and then stored in the desiccator overnight, or until their use.

\subsubsection{SECM procedures}

2.2.5.1. Modification of SECM tip electrode for imaging of enzyme substrate. A $25 \mu \mathrm{m}$ Pt tip electrode was scanned in a solution of ferrocenemethanol to ensure that the expected electrochemical response was achieved. If deemed necessary the tip electrode was activated in $0.5 \mathrm{M} \mathrm{H}_{2} \mathrm{SO}_{4}$ as described in section 2.2.3. The tip was then modified with a PEDOT film as described above (2.2.3.1), following which Th-fMWNT was incorporated over a $2 \mathrm{~h}$ time frame by cathodic constant potential deposition at $\mathrm{E}_{\mathrm{app}}=-0.5 \mathrm{~V} v \mathrm{~s}$. $\mathrm{Ag} / \mathrm{AgCl}$ (PEDOT/ Th-fMWNT).

2.2.5.2. SECM substrate generation - tip collection (SG-TC) imaging for $N A D H$ reactivity. The PEDOT/Thionine layer under investigation was deposited onto the Pt substrate electrode $(\mathrm{d}=2 \mathrm{~mm})$, rinsed to remove any unbound thionine and inserted into the SECM cell. The unmodified tip electrode was a $25 \mu \mathrm{m}$ Pt microelectrode (cleaned and activated as above) and was placed into the tip holder so as to barely touch the substrate electrode and then withdrawn a safe distance $(z / \mu \mathrm{m})$ in order not to touch the film during imaging. Imaging was carried out at a rate of $500 \mu \mathrm{m} \mathrm{s}^{-1}$ for all images. The substrate electrode was maintained at the reduction potential of the thionine in the PEDOT film $(-0.2 \mathrm{~V}$ vs $\mathrm{Ag} / \mathrm{AgCl})$ while the tip $(+0.1 \mathrm{~V}$ vs $\mathrm{Ag} / \mathrm{AgCl})$ played the role of generating oxidised thionine sites thus triggering NADH electrocatalysis (Scheme 1 (a)) using substrate generation-tip collection mode. 
stability. The PEDOT/Thionine layer under investigation was deposited onto the Pt substrate electrode ( $\mathrm{d}=2 \mathrm{~mm}$ ), rinsed well to remove any unbound thionine and inserted into the SECM cell. The unmodified tip was placed into the tip holder so as to barely touch the substrate electrode and then withdrawn a safe distance $(z / \mu \mathrm{m})$ in order not to touch the film during imaging. Imaging was performed at a rate of $500 \mu \mathrm{m} \mathrm{s}^{-1}$ in all cases. The substrate electrode was maintained at the reduction potential of the thionine/PEDOT film $(-0.5 \mathrm{~V}$ vs $\mathrm{Ag} / \mathrm{AgCl})$ while the tip was held at the oxidation potential $(+0.4 \mathrm{~V}$ vs $\mathrm{Ag} / \mathrm{AgCl})$. (Scheme 1 (b)) so as to enable detection of leached thionine from the substrate modified film (PEDOT/Thionine).

2.2.5.4. SECM substrate generation - tip collection (SG-TC) imaging of $N A D H$ generation at lactate dehydrogenase modified electrode. The modified (PEDOT/Th-fMWNT) tip electrode was prepared as described above, while the substrate electrode was modified with $10 \mu \mathrm{L}$ of the enzyme-Th-fMWNT mixture (prepared according to section 2.2.2) and air dried for $1 \mathrm{~h}$. Imaging was carried out initially in $1 \mathrm{mM} \mathrm{NAD}^{+} / \mathrm{PBS}$ pH 7.4, E $\mathrm{E}_{\text {SUbSTRATE }}$ OFF $\mathrm{E}_{\mathrm{TIP}}$ : $+0.3 \mathrm{~V}$ vs. $\mathrm{Ag} / \mathrm{AgCl}$. $5 \mathrm{mM}$ Lactate was added to solution and the image repeated to detect the NADH generated at the tip electrode (Scheme 1 (c)). This mode generated catalytic signals associated with substrate generated NADH at a thionine modified tip, thus enabling the lactate dehydrogenase enzyme layer reactivity to be imaged in the presence of enzyme substrate (lactate).

\subsubsection{UV analysis - determination of thionine concentration in PEDOT films}

UV-visible spectroscopy was performed using aqueous solutions of thionine (10-70 $\mu \mathrm{M}$ in PBS $\mathrm{pH}$ 7.4) and the molar extinction coefficient ( $\varepsilon 22814 \mathrm{M}^{-1} \mathrm{~cm}^{-1}$ ) calculated and used to determine thionine concentration within the PEDOT films. UV analysis of the PEDOT/Thionine films was achieved using a PEDOT film as background in order to eliminate any interference from the UV absorption of the PEDOT film itself.

\subsubsection{Scanning electron microscopy analysis}

PEDOT/Th-fMWNT films were prepared on Pt electrodes as described in section 2.2.3.1. Rinsed well with deionised water and dried overnight. The electrodes were analysed dry without sputter coating using an accelerating voltage of $5 \mathrm{kV}$.

\section{Results and discussion}

\subsection{Formation of Thionine-PEDOT and PEDOT/Thionine films}

These electrodes were prepared as described above (2.2.3.1) where thionine was incorporated into a PEDOT film both (a) during [Thionine/PEDOT] and (b) following [PEDOT/Thionine] electropolymerisation at Pt electrodes. In the case of the former (a), the thionine concentration must be sufficiently high such that PEDOT polymerisation is hindered, enabling sufficiently high thionine loading to be realised. Thionine has a tendency to form aggregates in solution if the concentration is too high (Nicotra et al., 2008), which can influence film reproducibility and performance. This approach (a) is based on prior work in our group (Warren et al., 2010) which generated an NADH electrocatalytic layer with subsequent glutamate detection (at glutamate dehydrogenase modified electrodes). Further optimisation of this immobilisation approach was deemed necessary in order to improve thionine loading and uniformity (hence approach (b) as outlined below). The assistance of scanning probe electrochemical methods and charge transport investigations also enabled successful lactate biosensing at a lactate dehydrogenase modified electrode (LDH-Th-fMWNT).

Incorporation of thionine into a PEDOT film following electropolymerisation [PEDOT/Thionone (b)], via the subsequent application of a reduction potential $(-0.5 \mathrm{~V} \mathrm{vs} . \mathrm{Ag} / \mathrm{AgCl})$ in the presence of $0.5 \mathrm{mM}$ thionine allowed for better control of thionine loading. The thickness of the PEDOT layer was critical in that it must be sufficient to give uniform coverage of the electrode area and be capable of retaining a suitable volume of thionine, but not so thick so as to hinder charge transport to the electrode surface. Thionine loading using this approach can be controlled using the timescale of the experiment at thionine concentrations where aggregation is eliminated. A comparison of the electrochemistry of two such films indicated enhanced thionine redox activity in the case of the film formed by incorporation of thionine following PEDOT formation via chronocoulometry [PEDOT/Thionine]. Voltammetric responses (data not shown) resulted in $\mathrm{E}_{\mathrm{p}(\mathrm{a})}=-0.02 \mathrm{~V}$ and $\mathrm{E}_{\mathrm{p}(\mathrm{c})}=-0.5 \mathrm{~V}$ with $\Delta \mathrm{E}_{\mathrm{p}}=0.43 \mathrm{~V}$ and $\mathrm{E}_{1 / 2}=-0.215 v \mathrm{~s}$. $\mathrm{Ag} / \mathrm{AgCl}$ for the 2 electron 1 proton process at $\mathrm{pH} 7.4$ (scan rate $0.1 \mathrm{Vs}^{-1}$ ).

\subsection{Reactivity of PEDOT/Thionine films by SECM imaging with NADH in solution}

Films were analysed using SECM (at a $25 \mu \mathrm{M}$ Pt tip electrode) in the presence of $1 \mathrm{mM} \mathrm{NADH}$ in order to determine the uniformity of the reactive layer on the electrode surface (Format (a) in Scheme 1). The considered mechanism for this process is that the tip is close enough to the modified surface in order to influence the regeneration of the oxidised form of thionine and detect enhanced currents associated with the catalytic interaction of thionine (ox) and NADH at the substrate modified PEDOT/Thionine layer).

Fig. 1 (a, b) shows SECM images of the redox films formed by the two different immobilisation methods, (a) where thionine was incorporated during PEDOT polymerisation (Warren et al., 2010) and (b) where the thionine was incorporated following PEDOT formation (as described above). It was apparent that method (b) produces a more uniformly reactive film with almost an order of magnitude higher $\left(3.95 \times 10^{-10} \mathrm{~A}\right)$ anodic response relative to that of (a) $\left(5.55 \times 10^{-11}\right.$ A). All films discussed from this point onwards were prepared using method (b) as described above in section 2.2.3.1.

\subsection{Influence of electrolyte type and polymerisation potential on PEDOT formation and thionine inclusion}

Dopant anions employed during the electropolymerisation procedure can have a profound effect on the resulting polymer. Smaller dopant anions can result in a denser polymer framework while the incorporation of larger anions can generate a more porous polymer structure (Abd-Elwahed and Holze, 2002). In this work the effect of using both $p$-toluenesulphonate and perchlorate as the dopant anions during PEDOT electropolymerisation was investigated. These films were analysed in terms of their ability to effectively 'load' thionine. As expected, when $p$-toluene sulphonate was used for PEDOT polymerisation, the time required to achieve maximum loading time (at $\mathrm{E}_{\mathrm{APP}}=-0.5 \mathrm{~V}$ ) from a $0.5 \mathrm{mM}$ thionine solution increased from $45 \mathrm{~min}$ (in the case of $\mathrm{ClO}_{4}{ }^{-}$) up to $75 \mathrm{~min}$ for the larger anion (sodium $p-$ toluene sulphonate). These results support the idea that the larger the dopant anion the more porous the film and therefore a longer time is required to obtain a stable saturation thionine film concentration. Fig. 1(c) shows a comparison of cyclic voltammograms of PEDOT/ Thionine films prepared in the presence of (a) perchlorate, and (b) $p$ toluene sulphonate, following $45 \mathrm{~min}$ thionine inclusion time (at $-0.5 \mathrm{~V}$ vs. $\mathrm{Ag} / \mathrm{AgCl}$ in $0.5 \mathrm{mM}$ thionine). Results indicated that the thionine oxidation and reduction peaks were more evident in the case of the sodium $p$-toluene sulphonate film and resulted in a smaller $\Delta \mathrm{E}_{\mathrm{P}}$ $\left(104 \mathrm{mV}\right.$ vs. $228 \mathrm{mV}$ ) relative to films formed from $\mathrm{LiClO}_{4}$. Therefore $0.1 \mathrm{M}$ sodium $p$-toluene sulphonate was chosen as the preferred electrolyte for further PEDOT electropolymerisation studies. The effect of PEDOT electropolymerisation potential was also investigated during chronocoulometric film formation. As expected, when $\mathrm{E}_{\mathrm{APP}}$ was reduced from +1.2 to $+0.8 \mathrm{~V}$ vs. $\mathrm{Ag} / \mathrm{AgCl}$, the time taken to obtain $79.6 \mathrm{mC} \mathrm{cm}{ }^{-2}$ increased significantly. No dramatic difference in 
a)

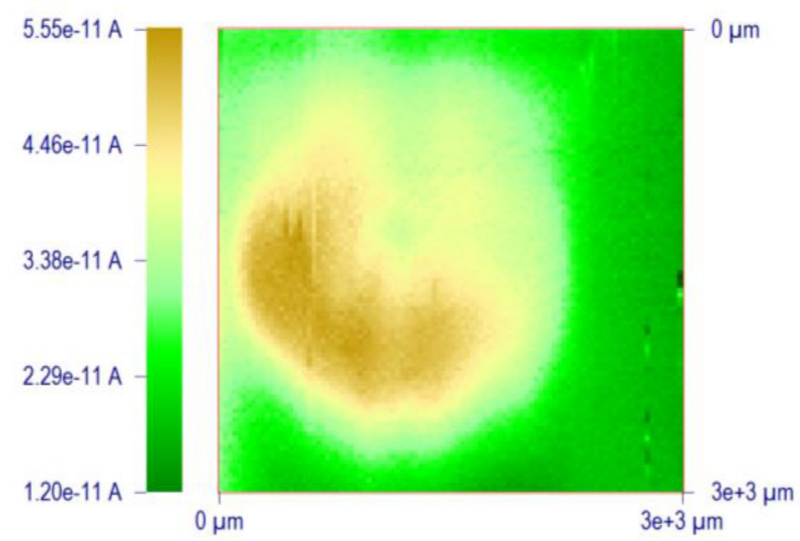

c)

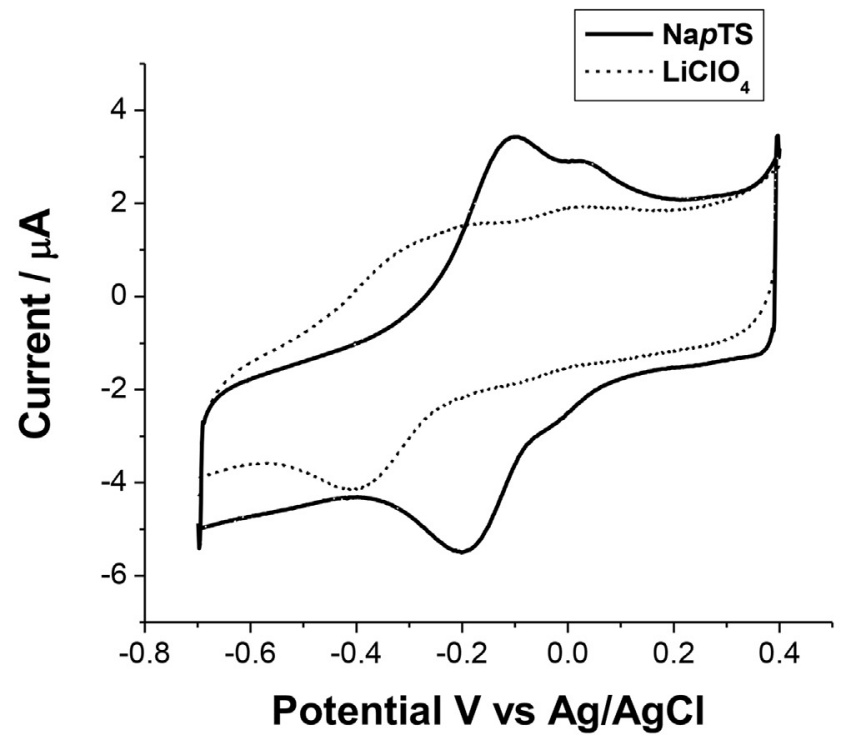

b)

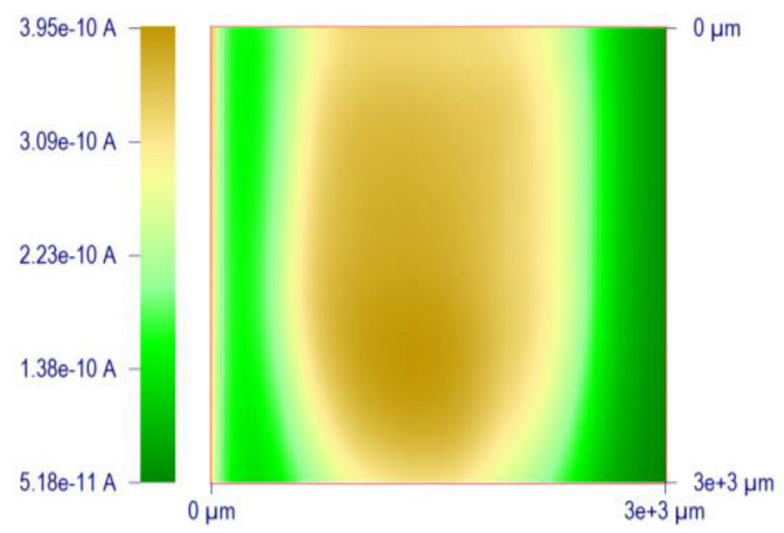<smiles>Nc1ccc2c(c1)Sc1cc(N)ccc1N2</smiles><smiles>N=c1ccc2nc3ccc(N)cc3sc-2c1</smiles>

Fig. 1. SECM imaging at $500 \mu \mathrm{m} \mathrm{s}^{-1}$ in $1 \mathrm{mM}$ NADH, PBS pH 7.4, $\mathrm{E}_{\text {SUBSTRATE }}-0.2 \mathrm{~V}$ vs Ag/AgCl, $\mathrm{E}_{\mathrm{TIP}}+0.1 \mathrm{~V}$ vs $\mathrm{Ag} / \mathrm{AgCl}$, $z-80 \mu \mathrm{m}$; for films formed by thionine incorporation (a) during PEDOT electropolymerisation (Thionine-PEDOT) and (b) after PEDOT electropolymerisation (PEDOT/Thionine), (c) cyclic voltammograms of PEDOT/Thionine films formed using $\mathrm{LiClO}_{4}$ or sodium p-toluene sulphonate (NapTS) as electropolymerisation electrolyte, 45 min thionine inclusion period. Associated redox processes for thionine proton dependant reduction to Leucothionine and oxidation to the radical cation form.

thionine loading between the films formed at different potentials was observed, and therefore the optimum, $+1.2 \mathrm{~V}$ vs. $\mathrm{Ag} / \mathrm{AgCl}$ was employed for all film formation.

\subsection{UV-visible spectroscopic analysis of PEDOT/Thionine films}

UV spectra were obtained for an aqueous solution of thionine $(0.5 \mathrm{mM})$, and each PEDOT/Thionine film prepared on ITOs as per section 2.2.4 using either $\mathrm{LiClO}_{4}$ or p-toluene sulphonate electrolyte. Free thionine showed a sharp band at $\lambda_{\max } 600 \mathrm{~nm}$ ( $\alpha$ band) attributed to the monomeric form, and a shoulder at $560 \mathrm{~nm}$ ( $\beta$ band) which may be attributed to higher aggregates of thionine (Guadalupe et al., 1991; Tamilarasan and Natarajan, 1981). For the PEDOT/Thionine films formed on ITOs the $\lambda_{\max }$ was observed at $570 \mathrm{~nm}$, attributable to the large thionine aggregation within the film with higher wavelength signal at $620 \mathrm{~nm}$. The absorbance ratios of the two signals for the ITO loaded films were close to 1:1 or 0.51:0.49 (and did not change upon varying thionine concentration), whereas for the solution of free thionine the absorbance ratios were 0.4:0.6 (560:600 $\mathrm{nm})$, which based on prior reports, implies that the red shift of the band at $600 \mathrm{~nm}$ may be attributed to oligomer formation via electron releasing groups $\left(\mathrm{NH}_{2}\right.$ pendant groups) and the proposed $\mathrm{N}-\mathrm{C}$ coupling forming nitrogen bridges between monomer units (Nicotra et al., 2008; Viswanathan and Natarajan, 1996). A similar red shift of 10 and $20 \mathrm{~nm}$ (respectively) was evident in our system in the case of both peaks.

\subsection{Effect of thionine loading on $D_{C T}$ values obtained via chronoamperometry}

PEDOT films were loaded with thionine as per section 2.2.3.1 over time periods $15-90 \mathrm{~min}$ in order to determine the optimum/maximum thionine incorporation time. Chronoamperometric measurements were carried out to determine the $\mathrm{D}_{\mathrm{ct}}$ values for each film in PBS electrolyte. ITO slides were prepared in parallel and analysed using UV-visible 
Table 1A

Thionine concentration levels for varying loading times into PEDOT/ $/ \mathrm{LiClO}_{4}$ with corresponding $\mathrm{D}_{\mathrm{CT}}$ values.

\begin{tabular}{lllllll}
\hline $\begin{array}{l}\text { Thionine } \\
\text { time/min }\end{array}$ & $\lambda / \mathrm{nm}$ & Absorbance & $\begin{array}{l}\text { Concentration } \\
/ \mathrm{mol.cm}^{-3} \mathrm{a}\end{array}$ & & \% Loading & $\begin{array}{l}\mathrm{D}_{\mathrm{CT}} \\
/ \mathrm{cm}^{2} . \mathrm{s}^{-1}\end{array}$ \\
\hline 15 & 566 & 0.215 & $4.06 \times 10^{-6}$ & 37.8 & $36.44 \times 10^{-8}$ \\
30 & 571 & 0.327 & $6.18 \times 10^{-6}$ & 57.8 & $9.56 \times 10^{-8}$ \\
45 & 572 & 0.57 & $10.78 \times 10^{-6}$ & 100 & $1.89 \times 10^{-8}$ \\
60 & 571 & 0.495 & $9.36 \times 10^{-6}$ & 87.1 & $3.47 \times 10^{-8}$ \\
75 & 571 & 0.428 & $8.09 \times 10^{-6}$ & 75.5 & $8.82 \times 10^{-8}$ \\
\hline a Concentration & calculated from & Beer & Lambert & Law & applying & $\varepsilon$ \\
\hline
\end{tabular}
$2.2814 \times 10^{4} \mathrm{M}^{-1} \mathrm{~cm}^{-1}$, where $1=0.001 \mathrm{~cm}$.

Table 1B

Thionine concentration levels for varying loading times in PEDOT/sodium -ptoluene sulphonate and corresponding $\mathrm{D}_{\mathrm{CT}}$ values.

\begin{tabular}{llllll}
\hline $\begin{array}{l}\text { Thionine } \\
\text { time/min }\end{array}$ & $\lambda / \mathrm{nm}$ & Absorbance & $\begin{array}{l}\text { Concentration } \\
/ \mathrm{mol}^{-\mathrm{cm}^{-3} \mathrm{~A}}\end{array}$ & $\%$ Loading & $\begin{array}{l}\mathrm{D}_{\mathrm{CT}} \\
/ \mathrm{cm}^{2} . \mathrm{s}^{-1}\end{array}$ \\
\hline 15 & 572 & 0.150 & $6.58 \times 10^{-6}$ & 69.8 & $12.75 \times 10^{-8}$ \\
30 & 573 & 0.205 & $8.99 \times 10^{-6}$ & 95.4 & $6.36 \times 10^{-8}$ \\
45 & 572 & 0.201 & $8.81 \times 10^{-6}$ & 93.5 & $5.84 \times 10^{-8}$ \\
60 & 572 & 0.206 & $9.03 \times 10^{-6}$ & 95.8 & $7.12 \times 10^{-8}$ \\
75 & 574 & 0.215 & $9.424 \times 10^{-6}$ & 100 & $3.432 \times 10^{-8}$ \\
90 & 572 & 0.209 & $9.161 \times 10^{-6}$ & 97.2 & $10.660 \times 10^{-8}$ \\
\hline
\end{tabular}

spectroscopy to measure the thionine concentration with respect to loading time. Table 1 (A) shows that thionine concentration within the PEDOT $/ \mathrm{LiClO}_{4}$ film increases up to $45 \mathrm{~min}$ and then starts to decrease. Therefore $45 \mathrm{~min}$ was taken as the maximum loading time for these films. Table 1(B) shows the corresponding data for PEDOT/sodium ptoluene sulphonate films indicating that an increase in thionine concentration with time occurred up to $75 \mathrm{~min}$, after which time it started to decrease. The main contrast between Table 1a) and b) is that thionine concentration shows a greater variation with loading time in the case of the PEDOT/ $\mathrm{LiClO}_{4}$ films. The PEDOT/sodium p-toluene sulphonate films show almost $70 \%$ loading after only $15 \mathrm{~min}$, in comparison to only $38 \%$ with the PEDOT/LiClO 4 . Both films exhibit similar thionine concentrations and comparable $\mathrm{D}_{\mathrm{CT}}$ values.

Both films demonstrate a dramatic decrease in $\mathrm{D}_{\mathrm{CT}}$ as the thionine loading increases. This trend suggests a principal role of physical diffusion of the redox species in charge transport through the film, which would be evidence of a reduced mobility at high surface concentration (Warren et al., 2006; Komura et al., 2001; Somasundrum and Bannister, 1997). From this observation, the mechanism of charge transport can be considered as diffusion. These results are in agreement with a previous report by Guadalope et al. (Guadalupe et al., 1991), where the charge transport properties of thionine and other cationic dyes within a Nafion film were investigated. In comparison to this reported work, the $\mathrm{D}_{\mathrm{ct}}$ values for our system are higher $\left(18.9-364 \times 10^{-9} \mathrm{~cm}^{2} \mathrm{~s}^{-1}\right.$ in comparison to $1.4-28 \times 10^{-9} \mathrm{~cm}^{2} \mathrm{~s}^{-1}$ ). This improvement could be attributed to the use of the conducting polymer, PEDOT. It is worth noting that the PEDOT/NapTS film presents a higher $\mathrm{D}_{\mathrm{CT}}$ at maximum loading than it's counterpart, $3.4 \times 10^{-8} v$ s. $1.8 \times 10^{-8} \mathrm{~cm}^{2} \mathrm{~s}^{-1}$, suggesting that the PEDOT/sodium $p$-toluene sulphonate counterion framework allows for better diffusion of thionine within the film. Film studies from this point onwards refer to PEDOT films prepared with sodium $p$-toluene sulphonate and subsequently loaded with thionine.

\subsection{Characterisation of thionine-modified fMWNTs}

Previous work in our group (Warren et al., 2010) demonstrated that incorporation of nanotubes into the sensor design enhanced performance of the resulting glutamate dehydrogenase biosensor. By modifying MWNT with thionine using an approach similar to that of Wang et al. (2007), and then by incorporating them into a preformed PEDOT (a)

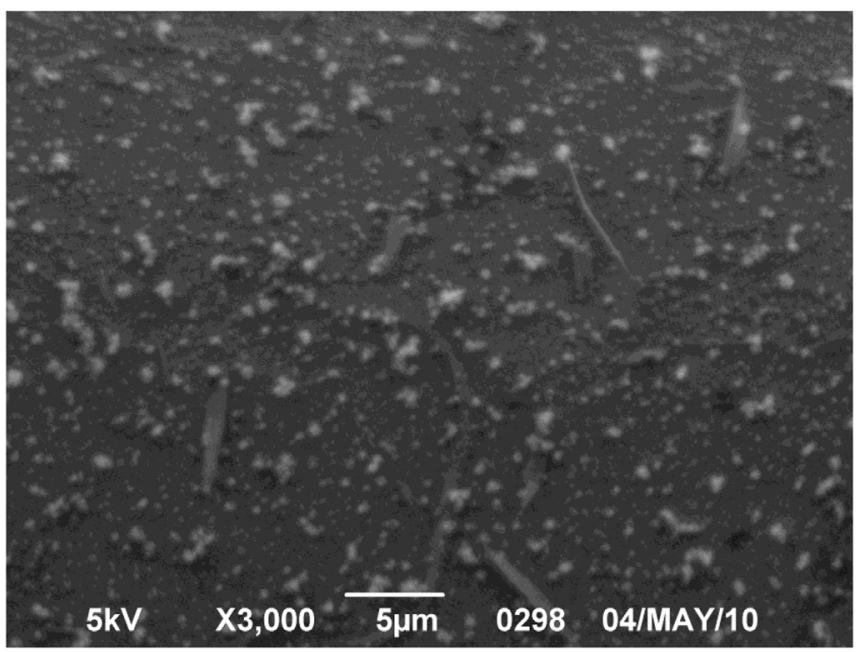

(b)

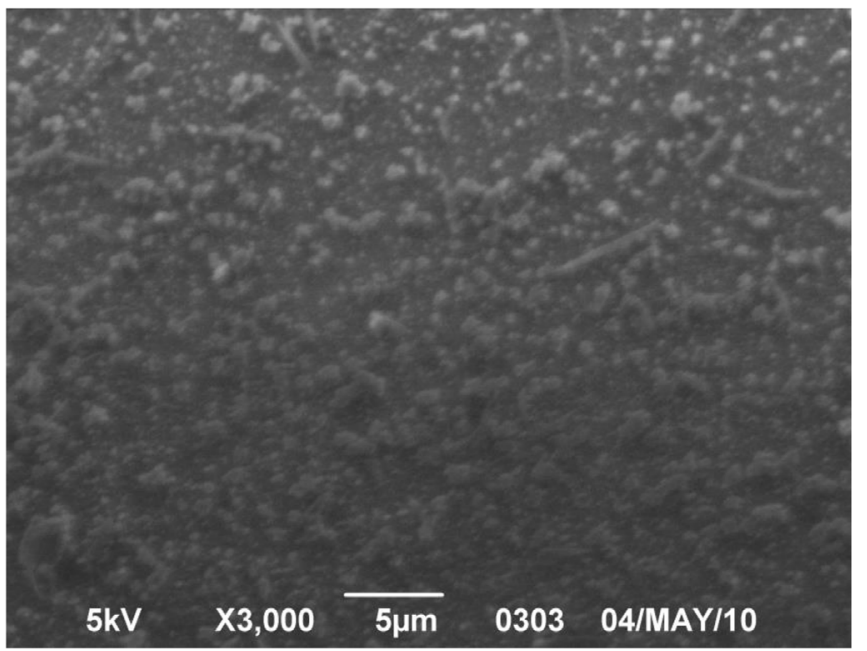

Fig. 2. SEM BEC images of PEDOT/Th-fMWNT films after a) $1 \mathrm{~h}$ and b) $2 \mathrm{~h}$ loading indicating increased surface density of thionine entrapped MWCNTs.

film ( $0.1 \mathrm{M}$ sodium p-toluene sulphonate), successful immobilisation of Th-fMWNT onto the electrode surface was achieved. SEM images of PEDOT/Thionine films are non-descript polymer films that have no distinct characteristic features. Fig. 2(a) and (b) shows the SEM images of the PEDOT/Th-fMWNT films for 1 and $2 \mathrm{~h}$ loading times. As is evident from these images, the polymer films exhibit a 'grainy' surface structure, which increases from 1 to $2 \mathrm{~h}$ loading time. This 'grainy' topography is attributed to the Th-fMWNT'S being incorporated into the PEDOT film.

\subsection{Stability study for PEDOT/Th and PEDOT/Th-fMWNT films using SECMIT imaging}

SECMIT imaging of PEDOT/Th and PEDOT/Th-fMWNT films was carried out by effectively monitoring the leaching of thionine from the film under investigation. Desorption was examined by rastering the tip electrode over the modified substrate electrode while subjecting it to a cathodic potential. Desorbed thionine can diffuse to the UME tip where it is oxidised, contributing to the tip current (Mirkin et al., 2001) from 


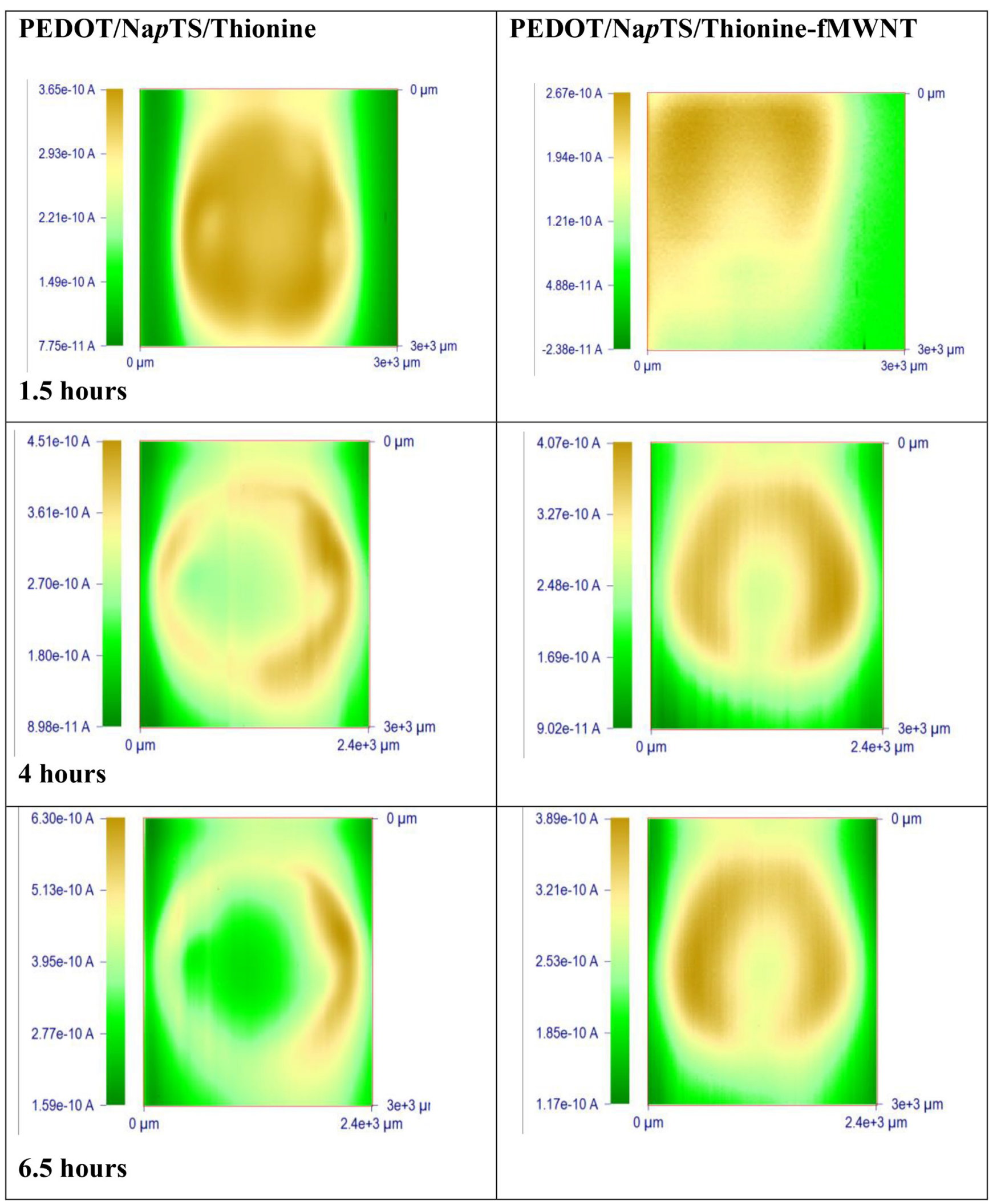

Fig. 3. SECMIT images of the leaching of thionine from prepared films over time (1.5-6.5 h) for both PEDOT/Thionine and PEDOT/Th-fMWNT surfaces. EsUBSTRATE: $0.5 \mathrm{~V}$ vs. $\mathrm{Ag} / \mathrm{AgCl}$ and $\mathrm{E}_{\mathrm{TIP}}:+0.4 \mathrm{~V}$ vs. $\mathrm{Ag} / \mathrm{AgCl}, z=-300 \mu \mathrm{m}$. 
the substrate. This procedure was repeated, monitoring the decrease in thionine from the film over time (working solutions were changed in between each image to minimise interference). Fig. 3 shows images of this process for (a) PEDOT/Thionine film and (b) PEDOT/ThioninefMWNT film over a continuous imaging period of $1.5-6.5 \mathrm{~h}$. As the imaging time increases, depletion of thionine was observed to be more significant in the case of the PEDOT/Thionine film as the brown electroactive layer becomes the green depleted area of the electrode. Imaging after $6.5 \mathrm{~h}$ showed no thionine response for the PEDOT/Thionine film, while the PEDOT/Th-fMWNT still exhibited a thionine signal up to and longer than $9 \mathrm{~h}$ imaging time. As expected, PEDOT/Th-fMWNT films leach thionine at a slower rate relative to PEDOT/Thionine films, due to the thionine being adsorbed in a more stable fashion onto the MWNT scaffold.

\subsection{SECM analysis of lactate dehydrogenase mounted on a solid support of Th- $f M W N T$}

Thus far we have demonstrated a novel immobilisation method of thionine into a preformed PEDOT polymer and have extended this methodology to incorporate thionine-modified MWNTs. Next, the biocatalyst lactate dehydrogenase (LDH) was partially crosslinked to ThfMWNT using glutaraldehyde according to the procedure in 2.2.2. In the presence of $1 \mathrm{mM}$ cofactor $\mathrm{NAD}^{+}$, the substrate (lactate) was oxidised by the biocatalyst to pyruvate with formation of NADH, being then re-oxidised by the immobilised thionine layer. Increased anodic thionine signals at $0.0 \mathrm{~V}$ were monitored in response to increasing lactate additions $(0-50 \mu \mathrm{M})$ (the mechanism is based on that proposed previously by our group (Warren et al., 2010)). By monitoring the thionine film response to lactate additions an increased catalytic current was evident which corresponds to re-oxidation of the reduced NADH enzyme cofactor.

Fig. 4(a) shows a cyclic voltammogram of the LDH-Th-fMWNT deposited directly onto the surface of a glassy carbon electrode, with inset calibration plot for lactate additions in the presence of $1 \mathrm{mM} \mathrm{NAD}^{+}$, $\mathrm{E}_{\mathrm{APP}} 0.0 \mathrm{~V}$ vs $\mathrm{Ag} / \mathrm{AgCl}$. The calibration curve of lactate, is linear with respect to (conc.) $)^{1 / 2}$ with sensitivity $20.86 \mathrm{nA} \mathrm{mM}^{-1 / 2}$ ), standard deviation $13.8(\mathrm{n}=3)$ over the range $0.5-5 \mathrm{mM}$. Hence, this demonstrates some heterogeneity of the developed electrode which can be attributed to the effect of cross linking of the enzyme by glutaraldehyde and thionine, as previously reported by Juang et al. (2002). Analytical response to NADH alone resulted in sensitivity $3.71 \pm 0.3145 \mathrm{nA} \mathrm{mM}^{-1}$ $(n=3)$ with LOD of $0.186 \mu \mathrm{M}$ and $r^{2}$ of 0.9995 . The low operating voltage $\left(\mathrm{E}_{\mathrm{app}}=0.0 \mathrm{~V}\right.$ hydrodynamic amperometry) ensures minimal interference from electroactive species and from direct NADH surface oxidation signals.

SECM was then used to examine the enzyme activity of the enzyme deposit layer. Due to the high overpotential platinum towards NADH produced from the active LDHase enzyme in the presence of lactate, we opted to modify the tip electrode with a NADH sensitive layer - the stabilised PEDOT/Th-fMWNT film. The data presented in Fig. 4(b), in addition to that shown in Fig. 4(a), proves the analytical applicability of the developed electrode. The average current density of the substrate electrode in the presence of $5 \mathrm{mM}$ lactate increases 2 fold, from $3.7 \mu \mathrm{A} \mathrm{cm}^{-2}$ in the absence of lactate, to $7.0 \mu \mathrm{A} \mathrm{cm}^{-2}$ when lactate is added to the system. It should be noted that the data presented in Fig. 4(b) was obtained in conditions far from that optimal for SECM imaging (distance, $z$, between the tip and the substrate electrodes was chosen as $800 \mu \mathrm{m}$ to avoid direct contact between these electrodes). Under these conditions, activity of the substrate electrode with respect to lactate concentration is comparable with the activity of the electrode used for registration of the lactate calibration curve (inset Fig. 4(a)). The calculated value of current density for $5 \mathrm{mM}$ lactate is approximately equal to $8 \mu \mathrm{A} \mathrm{cm}^{-2}$. Consequently, the efficiency of the "generation-collection" mode of SECM using a tip electrode modified by the same film as the substrate electrode is close to $50 \%$, which also (a)

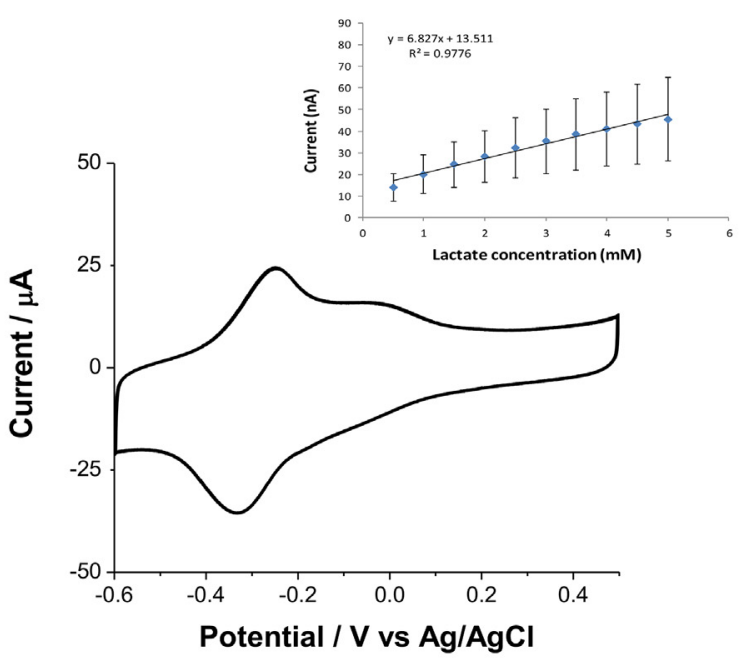

(b)

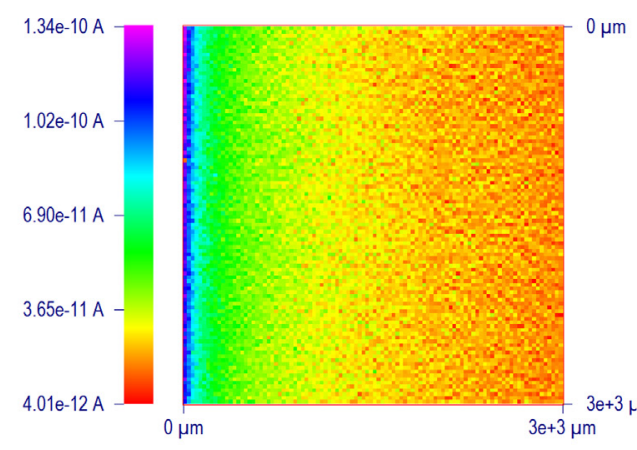

(c)

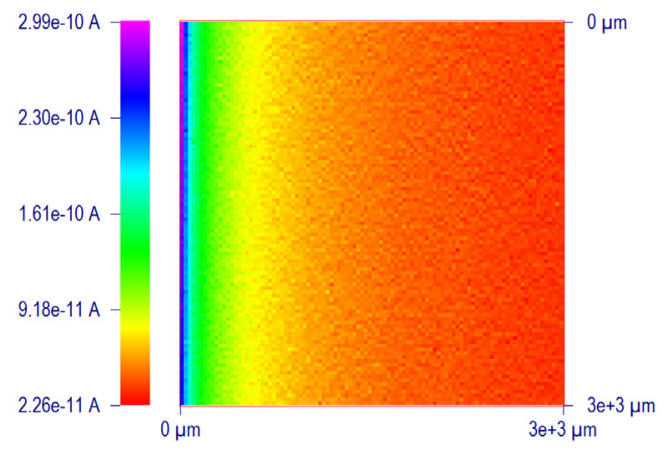

Fig. 4. (a) Cyclic voltammogram of lactate dehydrogenase modified thioninefMWNT and inset amperometric calibration plot for additions of $0.5 \mathrm{mM}$ lactate in the presence of $1 \mathrm{mM} \mathrm{NAD}^{+}$at $0.0 \mathrm{~V}$ vs. $\mathrm{Ag} / \mathrm{AgCl}$. Standard deviation across the analytical test range for lactate was 13.8 for $\mathrm{n}=3$ measurements at each concentration. (b) SECM images at a modified $25 \mu \mathrm{m}$ Pt tip electrode of LDH/ Th-fMWNT (substrate) in $1 \mathrm{mM} \mathrm{NAD}^{+}$in PBS and (c) LDH/Th-fMWNT in $1 \mathrm{mM}$

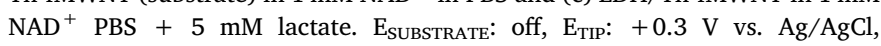
$z=800 \mu \mathrm{m}$.

confirms the analytical applicability of the developed electrode. Fig. 4(b), shows the increase in current generated after lactate is added to the system, confirming the activity of the enzyme on the thioninefMWNT support. This experiment demonstrates the ability of the thionine-fMWNT material to act as an electrocatalyst for NADH oxidation as well as a 'scaffold' for the attachment of dehydrogenase enzymes.

\section{Conclusions}

We have demonstrated a novel immobilisation method for thionine 
and thionine functionalised nanotubes, entrapped in a preformed PEDOT polymer film, examined with respect to surface electrochemical interrogation tools (SEM and SECM) and deployed in relation to lactate biosensing at a lactate dehydrogenase/thionine loaded modified electrode.

(a) Charge transport studies of thionine doped PEDOT films deduce that the mechanism of charge transport within the film was predominantly diffusion, as interpreted from the dramatic decrease in $\mathrm{D}_{\mathrm{CT}}$ as the thionine loading within the film increased. $\mathrm{D}_{\mathrm{CT}}$ values were of the magnitude $36.4 \times 10^{-8}-1.9 \times 10^{-8} \mathrm{~cm}^{2} \mathrm{~s}^{-1}$ and $12.8 \times 10^{-8}-3.43 \times 10^{-8} \mathrm{~cm}^{2} \mathrm{~s}^{-1}$ for PEDOT-Thionine films grown in the presence of lithium perchlorate and sodium $p$-toluene sulphonate respectively.

(b) SECM - induced transfer mode was employed as a tool to monitor the leaching of thionine from the PEDOT/Thionine films over time, resulting in the conclusion that thionine stability was enhanced using Th-fMWNT (prepared via electrostatic loading of thionine onto activated MWCNTs).

(c) It was also demonstrated that the Th-fMWNT can be used as a solid support for dehydrogenase enzymes through partial crosslinking of the respective thionine functional (amine) groups with lactate dehydrogenase. The resulting electrode was shown to be analytically applicable through the use of standard electrochemical techniques, $\mathrm{CV}$ and hydrodynamic amperometry.

(d) SECM experiments at the enzyme modified substrate electrode showed a two-fold increase in current density $\left(8 \mu \mathrm{Acm}^{-2}\right)$ when $5 \mathrm{mM}$ lactate was added to the system in the presence of $1 \mathrm{mM}$ $\mathrm{NAD}^{+}$. Analytical applicability of the developed sensor was also confirmed by the efficiency of the 'generation-collection' mode of SECM being close to $50 \%$.

Further work has the potential to expand the range of dehydrogenase systems under examination together with a kinetic evaluation of enzyme loaded films with the aid of suitable SECM quantitative and imaging modes.

\section{Declaration of interests}

The authors declare that they have no known competing financial interests or personal relationships that could have appeared to influence the work reported in this paper.

\section{Acknowledgements}

The authors acknowledge the Programme for Research in Third Level Institutions Cycle 4, Higher Education Authority for the financial support to carry out this work.

\section{References}

Abd-Elwahed, A., Holze, R., 2002. Ion size and size memory effects with electropolymerized polyaniline. Synth. Met. 131, 61-70.

Al-Jawadi, E., Poller, S., Haddad, R., Schuhmann, W., 2012. NADH oxidation using modified electrodes based on lactate and glucose dehydrogenase between an electrocatalyst film and redox catalyst modified polymers. Microchim. Acta 177, 405-410.

Amemiya, S., Bard, A.J., Fan, F.-R.F., Mirkin, M.V., Unwin, P.R., 2008. Scanning electrochemical microscopy. Annu. Rev. Anal. Chem. 1, 95-131.

Ashok Kumar, S., M Chen, S., 2008. Electroanalysis of NADH using conducting and redox active polymer/carbon nanotubes modified electrodes - a review. Sensors 8, 739-766.

Ates, M., 2013. A review study of biosensor systems based on conducting polymers. Mater. Sci. Eng. C 33, 1853-1859.

Balamurugan, A., Chen, S.-M., 2008. Voltammetric oxidation of NADH at phenyl azo aniline/PEDOT modified electrode. Sensor. Actuator. B 129, 850-858.

Balamurugan, A., Ho, K.-K., Chen, S.-M., Huang, T.-Y., 2010. Electrochemical sensing of NADH based on Meldola Blue immobilized silver nanoparticle-conducting polymer electrode. Colloid. Surf. Physicochem. Eng. Asp. 362, 1-7.

Bandyopadhyaya, R., Nativ-Roth, E., Regev, O., Yerushalmi-Rozen, R., 2002. Stabilization of individual nanotubes in aqueous solutions. Nano Lett. 2, 25-28.

Barker, A.L., Macpherson, J.V., Slevin, C.J., Unwin, P.R., 1998. Scanning Electrochemical Microscopy (SECM) as a probe of transfer processes in two phase systems: theory and experimental applications of SECM-induced transfer with arbitrary partition coefficients, diffusion coefficients and interfacial kinetics. J. Phys. Chem. B 102, 1586-1598.

Du, P., Liu, S., Wu, P., Cai, C., 2007. Single-walled carbon nanotubes functionalized with poly(nile blue A) and their application to dehydrogenase-based biosensors. Electrochim. Acta 53, 1811-1823.

Gao, Q., Cui, X., Yang, F., Ma, Y., Yang, X., 2003. Preparation of poly(thionine) modified screen-printed carbon electrode and its application to determine NADH in flow injection analysis system. Biosens. Bioelectron. 19, 277-282.

Gerard, M., Chaubey, A., Malhotra, B.D., 2002. Application of conducting polymers to biosensors. Biosens. Bioelectron. 17, 345-359.

Gonsalves, M., Macpherson, J.V., O'Hare, D., Winlove, C.P., Unwin, P.R., 2000. High resolution imaging of the distribution and permeability of methyl viologen dication in bovine articular cartilage using scanning electrochemical microscopy. Biochim. Biophys. Acta 1524, 66-74.

Guadalupe, A.R., Liu, K.E., Abruna, H.D., 1991. Transport properties of cationic dyes in Nafion films: unusually high diffusion coefficients and aggregation effects. Electrochim. Acta 36, 881-887.

Gurban, A., Noguer, T., Bala, C., Rotariu, L., 2008. Improvement of NADH detection using Prussian blue modified screen-printed electrodes and different strategies of immobilisation. Sensor. Actuator. B 128, 536-544.

Jain, R., Jadon, N., Pawaiya, A., 2017. Polypyrrole based next generation electrochemical sensors and biosensors: a review. Trac. Trends Anal. Chem. 97, 363-373.

Jing-Li, Z., Ping-Ping, N., Hai-Tao, Z., Ji-Mei, Z., 2009. Progress of electrochemical biosensors based on nicotinamide dinucleotide(phosphate)-dependent dehydrogenases. Chin. J. Anal. Chem. 37, 617-623.

Juang, R.-S., Wu, F.-C., Tseng, R.-L., 2002. Use of chemically modified chitosan beads for sorption and enzyme immobilisation. Adv. Environ. Res. 6, 171-177.

Kai, T., Zoski, C.G., Bard, A.J., 2018. Scanning electrochemical microscopy at the nanometer level. Chem. Commun. 54, 1934-1947.

Komura, T., Yamaguchi, T., Sato, H., Shimatani, H., Takahashi, K., 2001. Incorporation of 1,1'-dibenzyl-4,4'-bipyridium cation into Nafion films and charge transport in loaded film electrodes. Electrochim. Acta 46, 3579-3588.

Malhotra, B.D., Chaubey, A., Singh, S.P., 2006. Prospects of conducting polymers in biosensors. Anal. Chim. Acta 578, 59-74.

Maroneze, C.M., Arenas, L.T., Luz, R.C.S., Benvenutti, E.V., Landers, R., Goshikem, Y., 2008. Meldola Blue immobilized on a new SiO2/TiO2/graphite composite for electrocatalytic oxidation of NADH. Electrochim. Acta 53, 4167-4175.

Meng, Wu, P., Chen, G., Cai, C., 2008. Low overpotential detection of NADH and ethanol based on thionine single-walled carbon nanotube composite. J. Electroanal. Soc 155, F231-F236.

Mirkin, M.V., 2001. In: Bard, A.J., Mirkin, M.V. (Eds.), Scanning Electrochemical Microscopy. Marcel Dekker Inc., New York Ch. 5.

Morkvenaite-Vilkoncience, I., Ramanaviciene, A., Genyes, P., Ramanavicious, A., 2017. Evaluation of enzymatic kinetics of GOx-based electrodes by scanning electrochemical microscopy at redox competition mode. Electroanalysis 29, 1532-1542.

Nicotra, V.E., Mora, M.F., Iglesias, R.A., Baruzzi, A.M., 2008. Spectroscopic characterization of thionine species in different media. Dyes Pigments 76, 315-318.

Passos, M.L.C., Saraiva, M.L.M.F.S., Lima, J.L.F.C., 2010. A thionine-based reversible redox sensor on a sequential injection system. Anal. Chim. Acta 668, 41-46.

Persson, B., Gorton, L., 1990. A comparative study of some 3,7-diaminophenoxazine derivatives and related compounds for electrocatalytic oxidation of NADH. J. Electroanal. Chem. 292, 115-138.

Pierce, D.T., Unwin, P.R., Bard, A.J., 1992. Scanning Electrochemical Microscopy Studies of enzyme mediator kinetics for membrane and surface immobilised glucose oxidase. Anal. Chem. 64, 1795-1804.

Polcari, D., Dauphin-Ducharme, P., Mauzeroll, J., 2016. Scanning Electrochemical Microscopy: a comprehensive review of experimental parameters from 1989 to 2015. Chem. Rev. 116, 13234-13278.

Prieto-Simón, B., Macanás, J., Muñoz, M., Fàbregas, E., 2007. Evaluation of different mediator-modified screen-printed electrodes used in a flow system as amperometric sensors for NADH. Talanta 71, 2102-2107.

Rejeb, I.B., Arduini, F., Amine, A., Gargouri, M., Palleschi, G., 2007. Amperometric biosensor based on Prussian Blue-modified screen-printed electrode for lipase activity and triacylglycerol determination. Anal. Chim. Acta 594, 1-8.

Riggs, J.E., Guo, Z., Carroll, D.L., Sun, Y.-P., 2000. Strong luminescence of solubilized carbon naotubes. J. Am. Chem. Soc. 122, 5879-5880.

Rincon, R.A., Artyushkova, K., Mojica, M., Germain, M.N., Minteer, S.D., 2010. Structure and electrochemical properties of electrocatalysts for $\mathrm{NADH}$ oxidation. Electroanalysis 22 (7-8), 799-806.

Somasundrum, M., Bannister, J.V., 1997. Redox reactions in the presence of an ion-exchange/hydrogel composite film. Electroanalysis 9, 56-62.

Sun, P., Laforge, F.O., Mirkin, M.V., 2007. Scanning electrochemical microscopy in the $21^{\text {st }}$ century. Phys. Chem. Chem. Phys. 9, 802-823.

Tamilarasan, R., Natarajan, P., 1981. Photovoltaic conversion by macromolecular thionine films. Nature 292, 224-225.

Vasantha, V.S., Chen, S.-M., 2006. Synergistic effect of a catechin-immobilized poly(3,4 ethylenedioxythiophene)-modified electrode on electrocatalysis of NADH in the presence of ascorbic acid and uric acid. Electrochim. Acta 52, 665-674.

Vasilescu, A., Noguer, T., Andreescu, S., Calas-Blanchard, C., Bala, C., Marty, J.-L., 2003a. Strategies for developing NADH detectors based on Meldola Blue and screen-printed electrodes: a comparative study. Talanta 59, 751-765.

Vasilescu, A., Andrescu, S., Bala, C., Litescu, S.C., Noguer, T., Marty, J.-L., 2003b. Screen- 
printed electrodes with electropolymerized Meldola Blue as versatile detectors in biosensors. Biosens. Bioelectron. 18, 781-790.

Vigolo, B., Pénicaudl, A., Coulon, C., Sauder, C., Pailler, R., Journet, C., Bernier, P., Poulin, P., 2000. Macroscopic fibers and ribbons of orientated carbon nanotubes 290 , 1331-1334.

Viswanathan, K., Natarajan, P., 1996. Photophysical properties of thionine and phenosafranine dyes covalently bound to macromolecules. J. Photochem. Photobiol. A Chem. 95, 245-253.

Wang, Z., Li, M., Zhang, Y., Yuan, J., Shen, Y., Niu, L., Ivaska, A., 2007. Thionine-interlinked multi-walled carbon nanotube/gold nanoparticle composites. Carbon 45, 2111-2115.

Warren, S., McCormac, T., Mihaylova, E.M., Dempsey, E., 2006. Investigation into charge transport dynamics of $\left[\mathrm{Os}(\mathrm{bpy})_{2}\right.$ (picolinate) $] \mathrm{Cl}$ Nafion films. Electroanalysis 18 ,
1778-1785.

Warren, S., Rathod, D., McCormac, T., Dempsey, E., 2010. Investigations into the use of a thionine/PEDOT layer as an NADH electrocatalyst with applications in glutamate sensing. ECS Transactions 25, 21-32.

Wipf, D.O., 2001. In: Bard, A.J., Mirkin, M.V. (Eds.), Scanning Electrochemical Microscopy. Marcel Dekker Inc., New York Ch. 2.

Xia, L., Wei, Z., Wan, M., 2010. Conducting polymer nanostructures and their application in biosensors. J. Colloid Interface Sci. 241, 1-11.

Zhou, H., Zhang, Z., Yu, P., Su, L., Ohsaka, T., Mao, L., 2010. Noncovalent attachment of $\mathrm{NAD}^{+}$cofactor onto carbon nanotubes for preparation of integrated dehydrogenase based electrochemical biosensors. Langmuir 26, 6028-6032.

Zoski, C.G., 2016. Review - advances in scanning electrochemical microscopy. J. Electrochem. Soc. 163 (4), H3088-H3100. 